\title{
Development of New Preheating Methods for Hot Forging Tools Based on Industrial Case Studies and Numerical Modeling
}

\author{
MAREK HAWRYLUK, PAWEŁ WIDOMSKI, MARCIN KASZUBA, \\ and JAKUB KRAWCZYK
}

The study performs an overview and evaluation of the currently applied methods of preheating forging tools used in hot die forging processes performed on presses and presents the development and tests of new, more effective methods. Based on the conducted complex analysis of the temperature changes taking place on and directly beneath the surface of forging dies during their preliminary heating, an analysis was performed of one of the most commonly used methods of tool heating, i.e., using a charge material and a waste material. Next, the study proposes the introduction of changes and improvements of this method to achieve repeatability and stability of the obtained temperatures. To that end, detailed guidelines concerning the manner and time of the heating process were elaborated. The following step was the development of a new, more effective heating method. The first draft involved a new concept of heating using heaters localized in the die's housing or heaters in the shape of forgings placed between the dies. Both concepts of heating were numerically modeled, which made it possible to assess their effectiveness. The last step of the research was the development of a heating method using induction heaters. This method was the most effective and brought the best results, which was confirmed during the modeling of the heating process and in the tests conducted on the prototype test stand. The obtained results confirm the effectiveness of almost all the methods, especially the method of heating by means of a charge material, supported by new guidelines, the method of heating with the use of forging-shaped heaters and the method of induction heating. Only in the case of heating with heaters mounted in the tool housing was the assumed working temperature not achieved. Some differences were observed mainly related to efficiency, that is, the heating speed in respect to the assumed temperature. The performed tests showed that the best method is induction heating as it is over twice as fast. Therefore, it is usually recommended for the process of heating and the additional heating realized in the work center of the press on the mounted tools, where the time aspect is especially important.

https://doi.org/10.1007/s11661-020-05893-z

(C) The Author(s) 2020

\section{INTRODUCTION}

AMONG many metal-forming technologies, hot forging is commonly applied in the production of parts for the machine-building, agricultural, extractive, aircraft and, above all, automotive industry. At present, the main directions of forging industry development are concentrated on improving the quality of the forgings, among others, with the use of precision forging,

MAREK HAWRYLUK, PAWEL WIDOMSKI, MARCIN KASZUBA, and JAKUB KRAWCZYK are with the Department of Metal Forming, Welding and Metrology, Wroclaw University of Science and Technology, Lukasiewicza Street 5, 50-370 Wrockaw, Poland. Contact e-mail: marek.hawryluk@pwr.edu.pl

Manuscript submitted September 17, 2019.

Article published online July 9, 2020 improving the efficiency of the forging processes through their automatization, robotization and use of advanced production monitoring systems as well as lowering the production costs. ${ }^{[1,2]}$ Therefore, optimizing the amount of forging material and the whole forming process using FEM as well as increasing the durability of the forming tools used is being pursued. ${ }^{[3]}$

The tools used in hot forging processes are exposed to many detrimental factors, the most important of which is friction (abrasive wear), as well as varying temperatures and pressures (thermomechanical fatigue). ${ }^{[4]}$ The occurrence of these destructive mechanisms is inevitable, and they can only be limited by controlling the tool material and tool production technology. ${ }^{[8]}$ Additionally, in hot forging processes, during the tool's contact with the hot material of the forging, irregularities are seen, such as overheating or cracking as a result of 
non-uniform accelerated heating of the tool material. These problems should be eliminated by following proper tool cooling and performing preheating before the forging process begins to avoid non-uniform heating and its accompanying stresses. ${ }^{[9,10]}$ Proper preheating greatly increases the durability of the tool because it reduces the stress and thus directly helps avoid brittle fractures. ${ }^{[11,12]}$

The preheating of forging tools commonly takes place after they have been mounted on the forging aggregate (press or hammer), or directly before this, and the beginning of the forging process. In this field, the following methods are commonly used (Figure 1). The dies are usually heated using one or several gas flame burners. Often, the gas burners are arranged in a way to generate a diffused heat source on the surface of the dies (Figure 1(a)). Typical problems encountered in this heating method are carbon deposits, high noise, very significant temperature inhomogeneities and a large temperature difference between the upper and lower surface of the forging tools in the vertical configuration. Preheating is mainly carried out using thermal oil, electrical heat and guidance through the channels in the mold, or direct firing on the back of the mold, and dies using gas flames. Depending on the size of the tool, it can take several hours, which leads to huge production losses during regular repairs, and even more during spontaneous repairs. Direct heating of the dies by flame burners and temperature control are now widely used methods. These methods shorten the lifetime of forging tools. ${ }^{[13]}$

Another often used method is heating of the tool surface through its contact with the heated material assigned for the forging in the form of bars placed between the tools on the press (heating with a charge material or waste material) (Figure 1(b)). ${ }^{[14]}$ Sometimes, tool heating can be performed in a gas or electrical furnace; this is rarely done because of the difficulties of transporting and assembling hot tooling and the inefficiency. Some forging facilities also heat the tool surface with infrared lamps on the press/hammer or inside the furnace (Figure 1(c)). ${ }^{[11,15]}$ Sometimes, the problem is solved without preheating - the tools are covered with special separation substances (Figure 1(d)). ${ }^{[16]}$ Other methods have also been proposed but so far have not been commonly used, such as the application of induction coils or heaters with diverse shapes in the vicinity of the tools or introduced into the block of the die.

In the available literature, there are few publications concerning the analysis and use of various heating or warming up methods for forging tools. ${ }^{[17-25]}$ Anold's study ${ }^{[17]}$ indicated that dies should be preheated to $100{ }^{\circ} \mathrm{C}$. to $200{ }^{\circ} \mathrm{C}$ to avoid their failure, while a more contemporary work $^{[18]}$ proposes $205^{\circ} \mathrm{C}$ to $260{ }^{\circ} \mathrm{C}$. Several patents ${ }^{[19-22]}$ protect specific solutions of preheating or initial heating of forging tools. In handbooks, one can find only basic directions and tips about how preheating helps avoid failure. ${ }^{[23-25]}$ There are also solutions that maintain a constant tool temperature in the forging processes, especially those dedicated to forging titanium or aluminum alloys. ${ }^{[26,27]}$ More solutions can be found in the commercial sector-sometimes also patented solutions with devices or entire heating systems. For example, an alternative to die heating with flame burners is a commercial device called Airtorch ${ }^{\mathrm{TM}}$, which is a patented method to electrically heat air or gases. $^{[28,29]}$ With this device, it is possible to avoid problems such as carbon deposits, noise and the risk of explosions. The work ${ }^{[30]}$ presents the results of research concerning the homogeneity of temperature field distributions for two tool heating methods: electric, with the patented Airtorch ${ }^{\mathrm{TM}}$ device, and classic flame heating. The simulation results were verified based on the results of the experiments, which found that the electric heater is a better solution. Among the commercial solutions is the promeos ${ }^{\circledR}$ flameless gas burner, which creates direct heating systems and devices that adapt to the requirements and ensure quick and even heating of the forging dies and molds, without damaging the material. The intelligently integrated reo $^{\circledR}$, neo or ceo ${ }^{\circledR}$ burners from this company offer heat in the form of hot air, convection, semiconductor radiation and gas radiation from $100{ }^{\circ} \mathrm{C}$ to $1400{ }^{\circ} \mathrm{C}$. The areas of application of the promeos $^{\circledR}$ flameless gas burner are very diverse (Figure 2). The company has developed a new heating system with a flat radiation unit that can, for example, be moved between the molds using a manipulator or pallet truck. Going a step further, you can place it on the robot's arm. Then, the unique power density of the flameless burner allows effective heating of the mold in the targeted manner without damaging the material. For a variety of other tasks, such as preheating, promeos ${ }^{\circledR}$ gas heating is available as semiconductor radiation, convection or hot air in combination with secondary air. [31]

The Michigan Tech AME company, implementing a project sponsored by the Forging Industry Association, conducted research on the heating of forging dies. ${ }^{[32]}$ The preliminary results of the research showed that the greatest potential among the currently used methods is induction heating. Another example is Infrared Heating Technologies, which proposes infrared forging tool
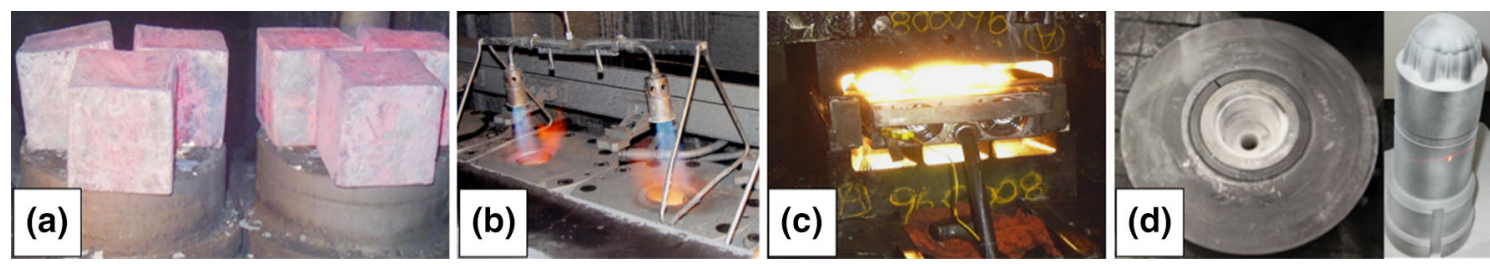

Fig. 1-Currently used forging tool heating methods: $(a)$ heated preforms, $(b)$ gas burners and $(c)$ infrared radiators. $(d)$ No preheating: application of separation methods, e.g., Aerodag Ceramishield welding foam. 

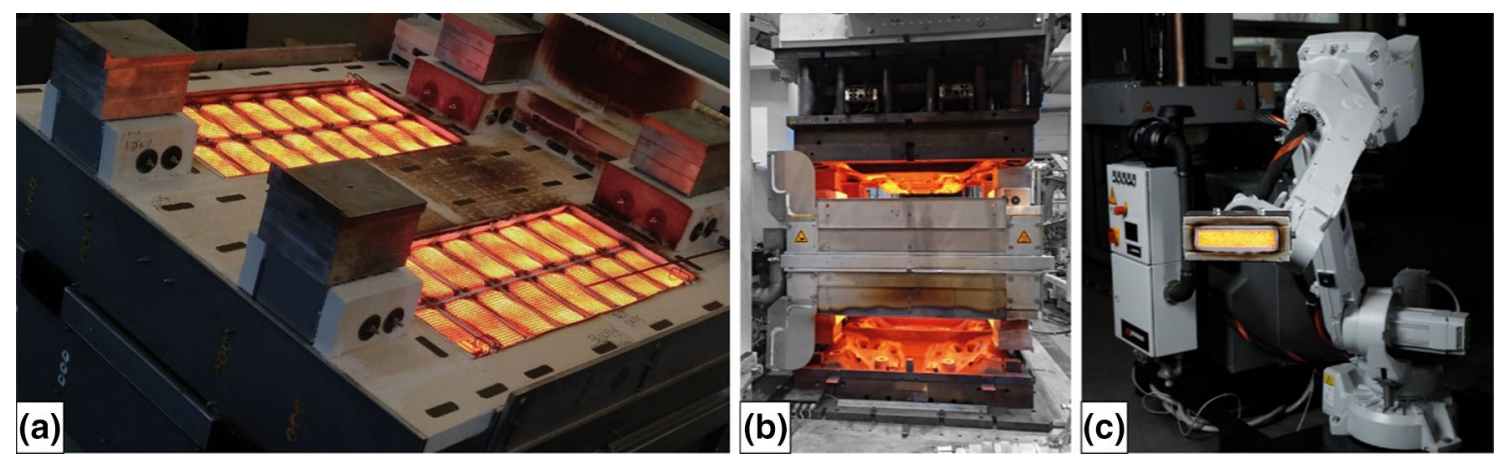

Fig. 2-View of the solution developed by promeos GmbH: (a) flameless gas burner technology; (b) mobile heating system; (c) robotically controlled flameless burning system for selective preheating. Reprinted with permission from promeos $\mathrm{GmbH}^{[31]}$

heating, and the suggested solution, Die Pre-HeaterTM, has $52.5 \mathrm{KW}$ power. ${ }^{[33]}$ Another interesting solution is electric heaters, proposed and verified by Russian scientists, which clearly increased the efficiency of heating and improved tool life. ${ }^{[34]}$

As can be seen, on the basis of the state-of-the-matter analysis, heating up of forging tools is a key factor ensuring, on the one hand, the correctness of the process and, on the other hand, the optimal tool durability. However, it still is a challenge and unresolved problem. Therefore, further research in this area was conducted in the contexts of both the development of science and new technology and the commercial aspect.

Recent studies have shown that the issues of preheating and tool temperature in the forging process can be solved by internal cooling. The research conducted on cooling channels through which the liquid flows has proved the possibility of controlling the temperature by regulating the temperature of the flowing liquid. ${ }^{[26]}$ This solution is not commonly used because of the difficulties in creating the fluid channels inside the tool, which are also a way of protecting its strength. An interesting solution to this problem is additively manufactured tools, in which the channels for the fluid temperature regulation can be modeled before manufacture. Then, by means of wire-arc additive manufacturing, a forging tool is built from scratch, taking into account the internal channels. ${ }^{[35]}$

The aim of the current research was to analyze the temperature of the forging dies during the preheating process and during the first working cycles and to develop preheating and additional heating technology between the maintenance shutdowns to ensure safe conditions for the forging tools' operation. According to the authors' experience, most people running forges know about the emerging new solutions for the preheating and reheating of forging tools. Nonetheless, the old and proven methods of heating are still used. The utilitarian purpose of this work is to convince the forging sector to start implementing modern heating systems (e.g., induction heating), whose efficiency is several times higher than that of the older methods, as demonstrated in this article.

\section{MATERIALS AND METHODS}

A detailed analysis was performed on the traditional heating methods using heated preforms of the charge material (at temperatures of about $1150{ }^{\circ} \mathrm{C}$ to $1200{ }^{\circ} \mathrm{C}$ ), assigned for the first operation, i.e., flattening, as well as the method of heating using specially designed heaters for selected tooling, and also induction heating. Verification tests were performed at the Jawor Forge on a Masseypress, load $13 \mathrm{MN}$, which carries out the process of hot forging of a yoke. It is conducted in three operations (flattening, preliminary forging and finishing forging), with a forging material temperature of $1150{ }^{\circ} \mathrm{C}$ to $1180{ }^{\circ} \mathrm{C}$. Detailed information concerning the forging process can be found in the studies. ${ }^{[36]}$ The tools used in this process are made of steel X37CrMoV5-1 and undergo thermal treatment through hardening and double tempering in furnaces without a protective atmosphere. Additionally, the preliminary and finishing tools are gas nitrided to improve their durability. This selection of material and technology allows obtaining tools that are resistant to high temperatures and adjusted to hot operations, with the tool temperature not exceeding $550{ }^{\circ} \mathrm{C}$. The recommended work temperature is $250^{\circ} \mathrm{C}$ to $300{ }^{\circ} \mathrm{C}$, and this temperature should be obtained as the preliminary value before beginning the forging process. Due to the difficulties in obtaining this temperature, it is acceptable for the preheating process to raise the temperature to $200{ }^{\circ} \mathrm{C}$; in the first few forging cycles, the temperature gradually rises until its value stabilizes at the expected level.

Within the performed research, a series of tests was performed, including measurement of the temperature of the tools, the heating material as well as other elements of the press for different heating variants. The tool temperature measurement was realized by a thermocouple introduced through the opening into the tool directly under the working pattern at the depth of 2 to 5 $\mathrm{mm}$ connected to a proprietary measuring system as well as by a fast thermovision camera and pyrometers. In this way, it was possible to verify the obtained results and perform a thorough analysis. 


\section{A. Analysis of Tool Temperature Changes During the Forging Process}

To measure the tool temperature directly underneath the impression, a thermocouple was placed in the selected tool, which was connected to a measuring system and mounted about 2 to $5 \mathrm{~mm}$ below the working surface of the lower roughing die insert. The measurement took place in real time. The obtained results are presented in Figure 3. The visible value leaps indicate single strokes of the forging press.

Simultaneously, during the forging process, temperature measurement was performed on the surface of the lower and upper tool as well as the deformed element using a fast thermovision camera. The results in the form of a thermogram, which is a color map showing the temperature distribution, are presented in Figure 4.

To ensure the longest possible operation time for tools made of X37CrMoV5-1 steel without damaging them (according to the material suppliers as well as the numerous studies performed so far), it is recommended that the tools should not be overheated during the process and the tool temperature during the process should not exceed $500{ }^{\circ} \mathrm{C}$, as this can cause material tempering and a loss of the functional properties in this area. Another recommendation is avoiding tool underheating before their operation to prevent non-uniform

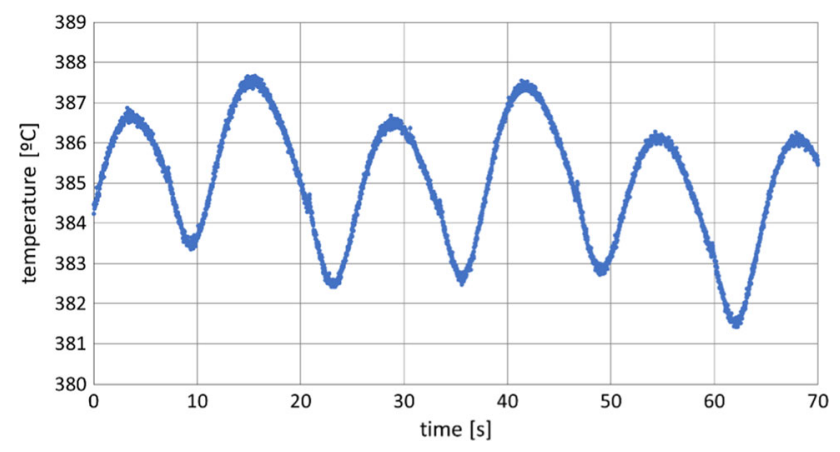

Fig. 3- Change in the tool temperature during the examined forging process (about $5 \mathrm{~mm}$ below the working surface). heating of the die material, which may cause excess stresses leading to premature damage and cracking of the tools.

The tool heating method that has been elaborated and applied by the forge up till now assumes that the tools should be preheated (before the forging process) to $200{ }^{\circ} \mathrm{C}$ to $250{ }^{\circ} \mathrm{C}$, which protects them from the formation of detrimental stresses as a result of too rapid heating in the first forging cycles. The method consists of heating portions of random geometry of the charge material cut from a bar up to $1150{ }^{\circ} \mathrm{C}$ and placing them on the surface of the lower tool. Next, because of lowering the press ram, the upper tools press down the hot material portions onto the lower tools. The heated material portions are also placed around the tools on the press table to create additional insulation with the hot material. Also, during the break (change of team, breakdown, etc.), similar steps are taken to maintain the tool temperature. Unfortunately, this heating method is uncontrolled and depends exclusively on the experience of the blacksmiths, which makes it unrepeatable and prone to unpredictable consequences. In addition, the long contact time of the heated preheaters with the tool heated to $>1000{ }^{\circ} \mathrm{C}$ may cause overheating of the tools and their surface tempering. This can affect the specialized protective layers (nitriding, hybrid layers, etc.) used on the tools and completely destroy the intended effect of increasing the resistance of the tools to destructive mechanisms. Figure 5 presents a graph of the influence of temperature and time on the tempering of steel for hot operations.

As can be seen, in principle, for each steel used for the tools, a temperature $>550{ }^{\circ} \mathrm{C}$ causes a significant reduction in hardness. A similar situation occurs in case of long-term holding times of these tool steels at elevated temperatures. ${ }^{[38]}$ The chart in Figure 5 shows that the higher the temperature with time, the more intensive the decrease in content. The repeated heating of the tools with the waste material can also have consequences by reducing the durability of the forging equipment.

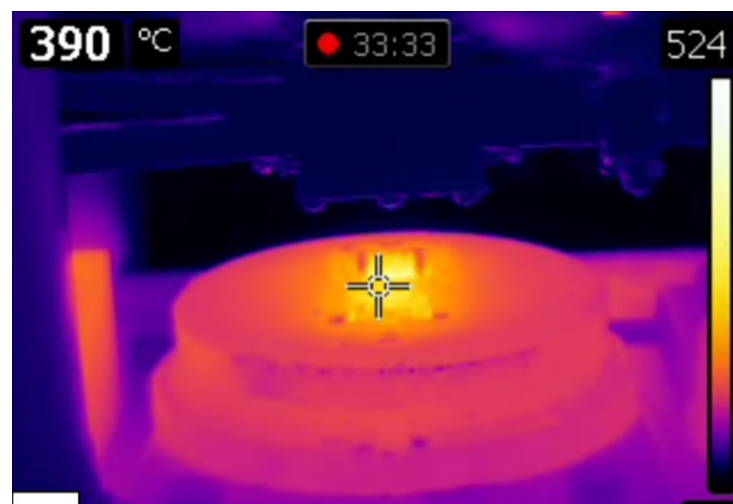

(a) LIR

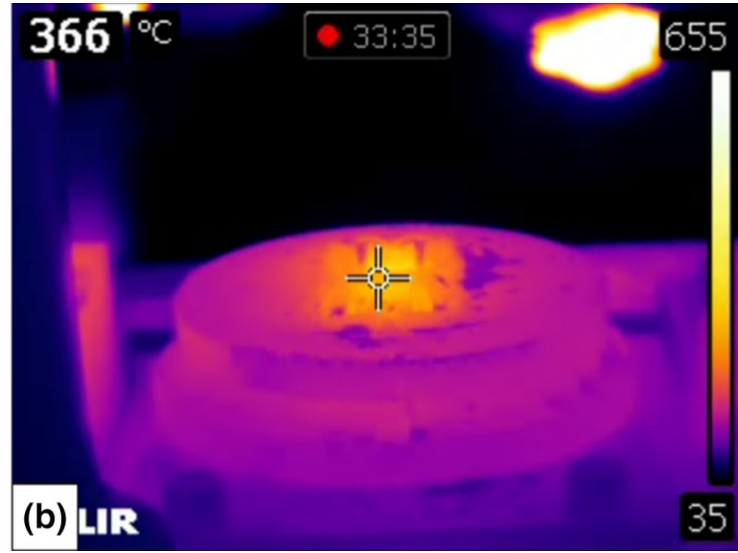

Fig. 4-Thermogram generated during the forging of yoke-type forgings: (a) before spraying; $(b)$ directly after spraying by lubricant. 


\section{ANALYSIS OF SELECTED METHODS OF TOOL HEATING: DISCUSSION OF RESULTS}

The research concerned various pre-heating methods and aimed to propose and verify a new method of heating, as an alternative to the one currently used, with the help of hot bars laid on the tool surface. Therefore, first, the effectiveness and efficiency of the currently used method were analyzed. The research was conducted with the aim to apply the method to preheat cold tools and reheat them during technologic breaks to maintain or restore the expected temperature. The temperature changes were measured by thermocouples entered into the tool under the cavity (about $2 \mathrm{~mm}$ below the surface) and at the bottom of the die. For all the proposed solutions, a numerical model was first constructed, in which the heating efficiency was preliminarily verified. Then, a prototype was built, on which the tests were carried out. The experiment included: heating of the charge/waste material, heating with patron heaters in various configurations and induction heating.

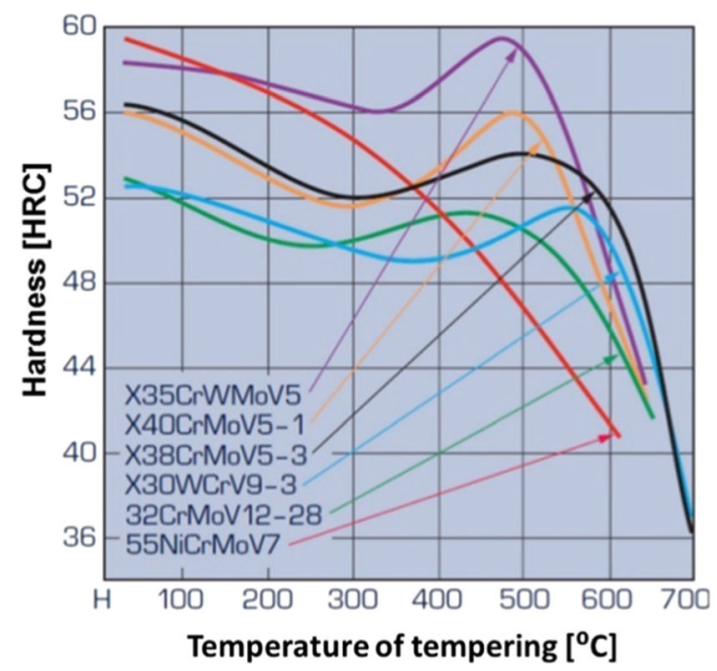

Fig. 5-Influence of temperature changes on the hardness of tool steel alloys for hot operations Reprinted with permission from Ref. [37].

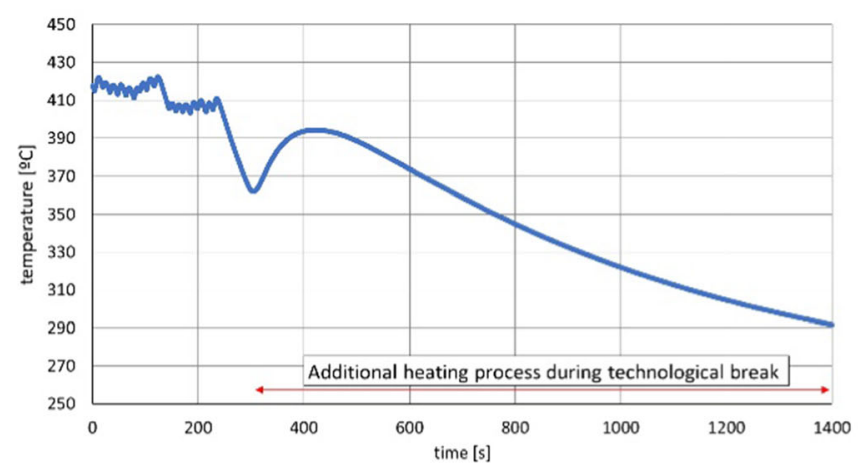

(a)

\section{A. Warmup by Waste Material}

First, the tool temperature was measured by a thermocouple introduced into the die directly beneath the surface from the inside. The course of the tool temperature changes measured with the thermocouple during the heating is shown in Figure 6; Figure 6(b) presents the course of the temperature changes during the forging of four forgings right after the maintenance shutdown.

After the tools have been heated, test forgings are prepared for measurement purposes. This demonstrated that the test forging of one or more forgings, combined with the regulation of the press table, despite longer inaction intervals, does not cause risky cooling of the tools, as one forging cycle is enough to raise the tool temperature by about $10^{\circ} \mathrm{C}$ to $15^{\circ} \mathrm{C}$, which balances the stoppage of the press for $100 \mathrm{~s}$ as well as the cooling of the tools proceeding at that time.

The currently applied method does not ensure long durability or tool operation time (Figure 7), as, during its implementation, workers might make mistakes, such as arranging preforms that are too hot, which, in the case of long contact with the heated material, can cause tempering of the tool material.

Based on the temperature tests, detailed procedures of tool preheating with a charge material were proposed (Figure 8). The procedure consists of eight steps marked with numbers 1 to 8 . Steps 1, 2, 4 and 6 involve stacking hot billets (at approximately $1150{ }^{\circ} \mathrm{C}$ to $1200{ }^{\circ} \mathrm{C}$ ) in rows. Steps 3, 5, 7 and 8 consist of laying billets cooled to a temperature around $1000{ }^{\circ} \mathrm{C}$ on the press around the tools and on their surface. Then, the press slider is lowered to clamp the heated material between the upper and lower tools. The obtained results confirmed the validity of heating using a heated charge material; however, for the temperature to rise $>200{ }^{\circ} \mathrm{C}$, the procedure should be performed two or even three times (Figure 9).

After the material portions have been arranged, they should be left for 10 minutes to let the heat exchange happen, and next the whole charge material should be removed. The whole sequence of steps should be performed twice or three times so that the optimal

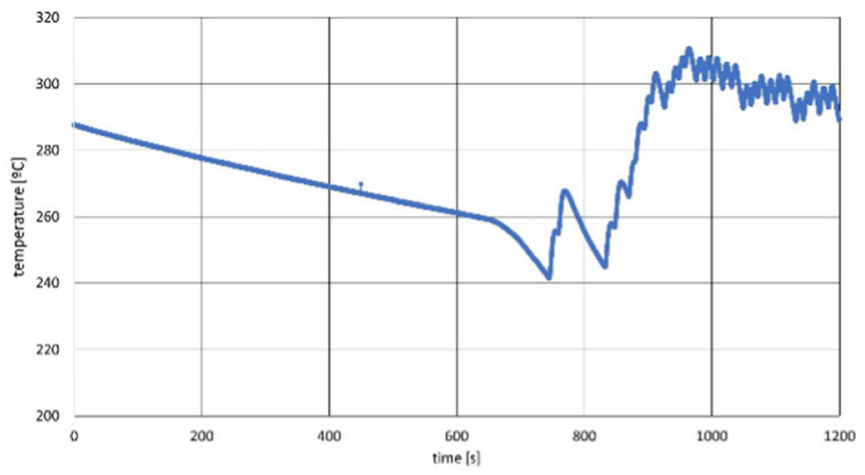

(b)

Fig. 6 - Changes in the tool temperature during (a) additional heating at the time of a maintenance shutdown; $(b)$ restart of the forging process after a technological break. 

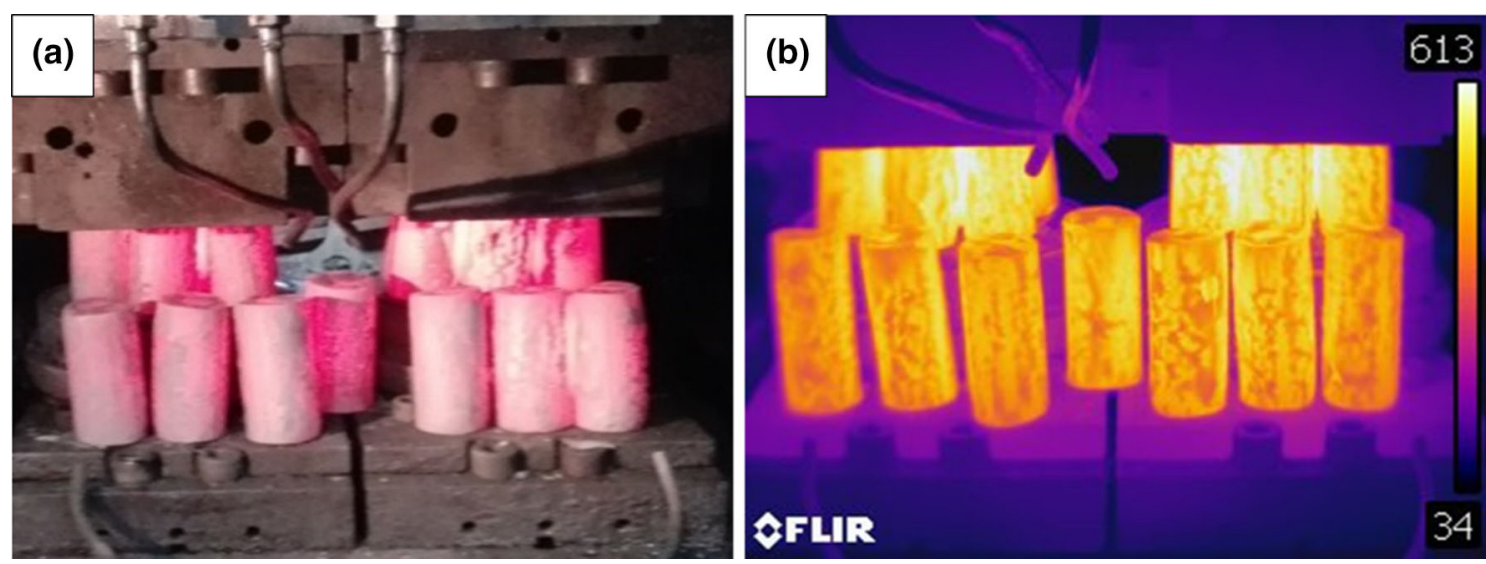

Fig. 7-Heating the tools with a charge or waste material: (a) the photo; $(b)$ the thermogram.

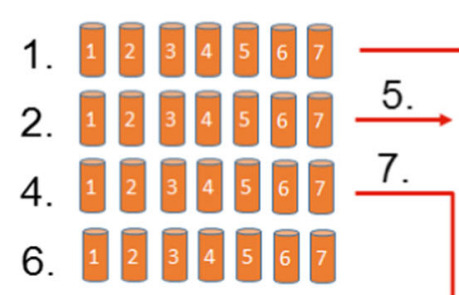

3.
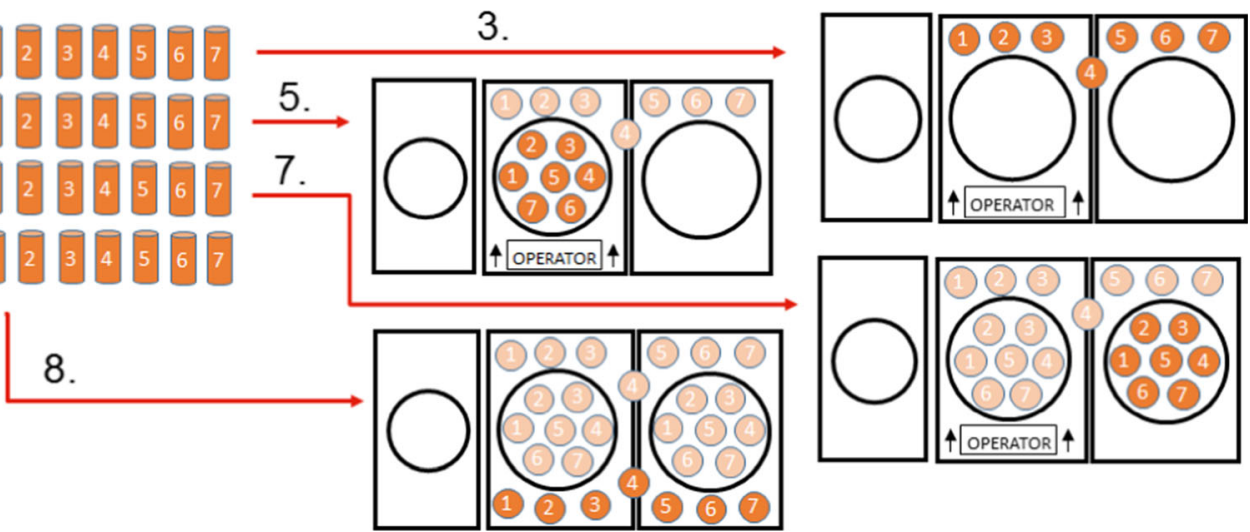

Fig. 8-Method, developed and recommended by the authors, of heating tools on a press through the proper placing of the heating charge material (the numbers indicate the order of the laying operations in rows next to the press or later on the tools and the press table).
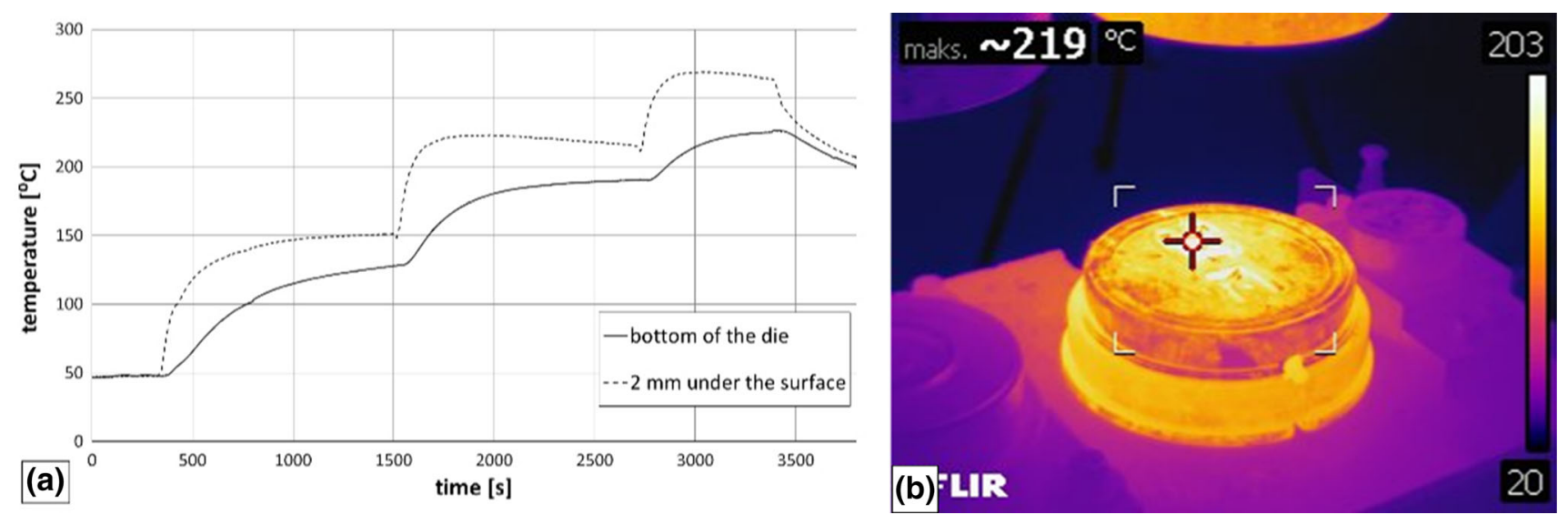

Fig. 9-View of: (a) the temperature inside the tool during three consecutive cycles of heating with a charge material; $(b)$ thermogram of a tool ready for work, heated according to the guidelines from Fig. 8.

temperature can be reached, i.e., about $200{ }^{\circ} \mathrm{C}$ to $250{ }^{\circ} \mathrm{C}$. To verify the effectiveness of the elaborated method and determine the time and number of heating cycles, a multiple heating test was performed, during which the tool temperature was measured with thermocouples at a depth of $2 \mathrm{~mm}$ beneath the surface as well as on the bottom of the tool. This was confirmed by the results obtained from both the measuring system (Figure 9(a)) and the thermovision camera (Figure 9(b)).

As was verified by the experiment, heating by means of hot waste material ensures obtaining a tool temperature within the range of $200^{\circ} \mathrm{C}$ to $250{ }^{\circ} \mathrm{C}$, which indicates the tools' readiness for the launch of a forging 
process. Unfortunately, to reach the expected temperature, three heating cycles need to be performed, which take $>50$ minutes. Even though the method ensures the proper conditions for the initiation of the forging process, it enforces a stoppage of the press, which lasts too long. Therefore, it is not recommended for use in the present production on automatized stands, as even a short stoppage generates losses from the interruption of the production process.

\section{B. Heating with Patron Heaters Placed in the Tool Housing}

To ensure a shorter heating time, the next stage of the authors' research concentrated on the elaboration of a more effective heating method, which would prevent overheating of the tools' surface layer. In the designing process, an additional assumption was made, i.e., that the elaborated solution was also to be used for the additional heating of sets of tools during enforced and non-enforced maintenance shutdowns or breakdowns.

All the studies were performed by way of numerical modeling, in which the effectiveness of the proposed solutions was preliminarily verified. The constructed model had all the geometrical and physical properties of real tooling, for which, to model the heat conduction, two extreme values of the heat transfer coefficient in contact were assumed, i.e., $2000 \mathrm{~W} / \mathrm{m}^{2}$ and $10,000 \mathrm{~W} /$ $\mathrm{m}^{2} \mathrm{KThe}$ first solution, which was supposed to ensure preheating of the tooling as well as additional heating during the maintenance shutdowns, were heaters mounted in the housing around the dies. Such an

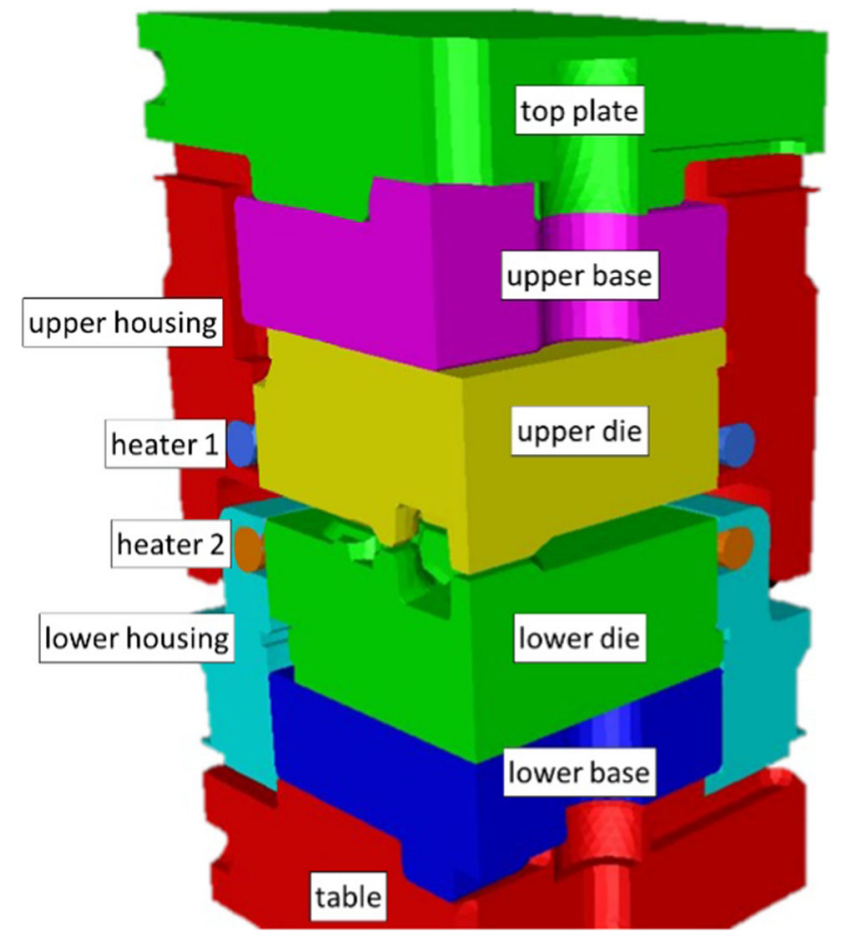

Fig. 10-Model of a heater mounted in the housings of forging dies on a press. integrated solution could enable heating at any moment, even during short breaks, without requiring any interference in the press window. Figure 10 shows a numerical model of this solution. The assumed initial values were: initial temperature of all the elements: $30{ }^{\circ} \mathrm{C}$; temperature of the heater: $500{ }^{\circ} \mathrm{C}$.

The numerical modeling with the MARC program showed the following effects, presented in Figure 11, referring to the temperature fields, for the two assumed variants of the heat transfer coefficient.

The modeling results can be summarized as follows:

- For the assumed coefficient $2000 \mathrm{~W} / \mathrm{m}^{2} \mathrm{~K}$, the temperature of the insert stabilizes after about 60 minutes and reaches the maximal value of about $50{ }^{\circ} \mathrm{C}$ for the external area of the die. The working pattern temperature is lower.

- For the assumed coefficient $10,000 \mathrm{~W} / \mathrm{m}^{2} \mathrm{~K}$, the die temperature stabilizes after about 40 minutes and reaches the maximal value (directly by the heater) of even $130{ }^{\circ} \mathrm{C}$. The working pattern temperature is already much lower and does not reach $>70{ }^{\circ} \mathrm{C}$.

- Unfortunately, one can suppose that, for the proposed system, the coefficient with the value of 2000 $\mathrm{W} / \mathrm{m}^{2} \mathrm{~K}$ would be appropriate, as the insert is not in direct contact with the heater; therefore, nearly all the heat is released into the housing.

- Also problematic is the fact that heating the housing will cause the latter to expand, which may have a negative effect on the mounting of the insert and may also reduce the contact of the housing with the tools, thus reducing the heat conduction to the tools.

\section{Heating with Patron Heaters Placed in a Forge Heating Element}

Since the solution presented above is not useful, a test stand was designed to heat the tools by introducing three cartridge heaters in the form of a "heating" forging (the forging geometry matched that of the tools' working cavity). To verify the effectiveness of the heating, a numerical model of the whole tool set was constructed (Figure 12). In the numerical modeling, two similar variants were analyzed, connected with different heat transfer coefficients: $10,000 \mathrm{~W} / \mathrm{m}^{2} \mathrm{~K}$, with the assumption of complete contact between the particular elements, and $2000 \mathrm{~W} / \mathrm{m}^{2} \mathrm{~K}$, as a more probable value, as the contact between the heaters and the dies is not good. ${ }^{[39,40]}$ The initial values were assumed as follows: initial temperature of all the elements: $30{ }^{\circ} \mathrm{C}$; temperature of the heater: $400{ }^{\circ} \mathrm{C}$.

As a result of the performed multi-variant computer simulations, including different initial temperatures of the heater as well as geometries, the most satisfactory temperature field distribution was obtained, ensuring the assumed working temperature of the tools for the two assumed variants (Figure 13). Based on the assumed heat transfer coefficients, it was established that the temperature would stabilize after 30 to 35 minutes. 

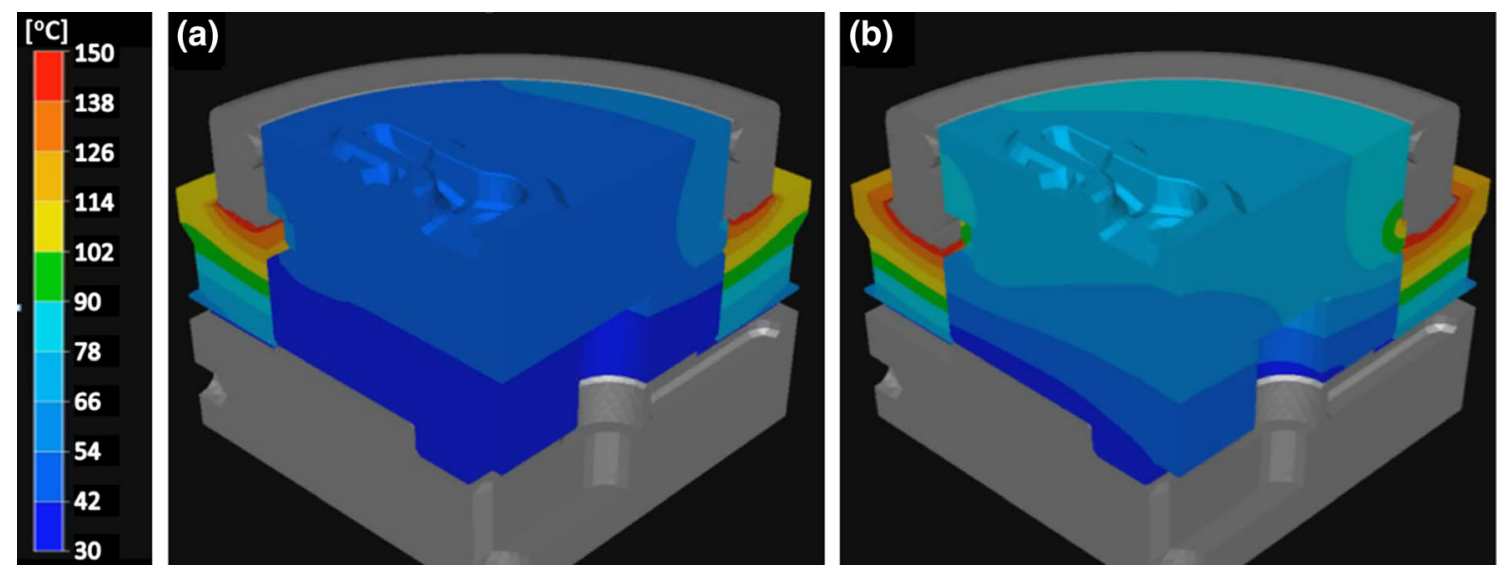

Fig. 11-Die heating modeling results, time of $120 \mathrm{~min}$, using heaters mounted in the housing: $(a)$ heat transfer coefficient: $2000 \mathrm{~W} / \mathrm{m}^{2} \mathrm{~K} ;(b)$ heat transfer coefficient: $10,000 \mathrm{~W} / \mathrm{m}^{2} \mathrm{~K}$.

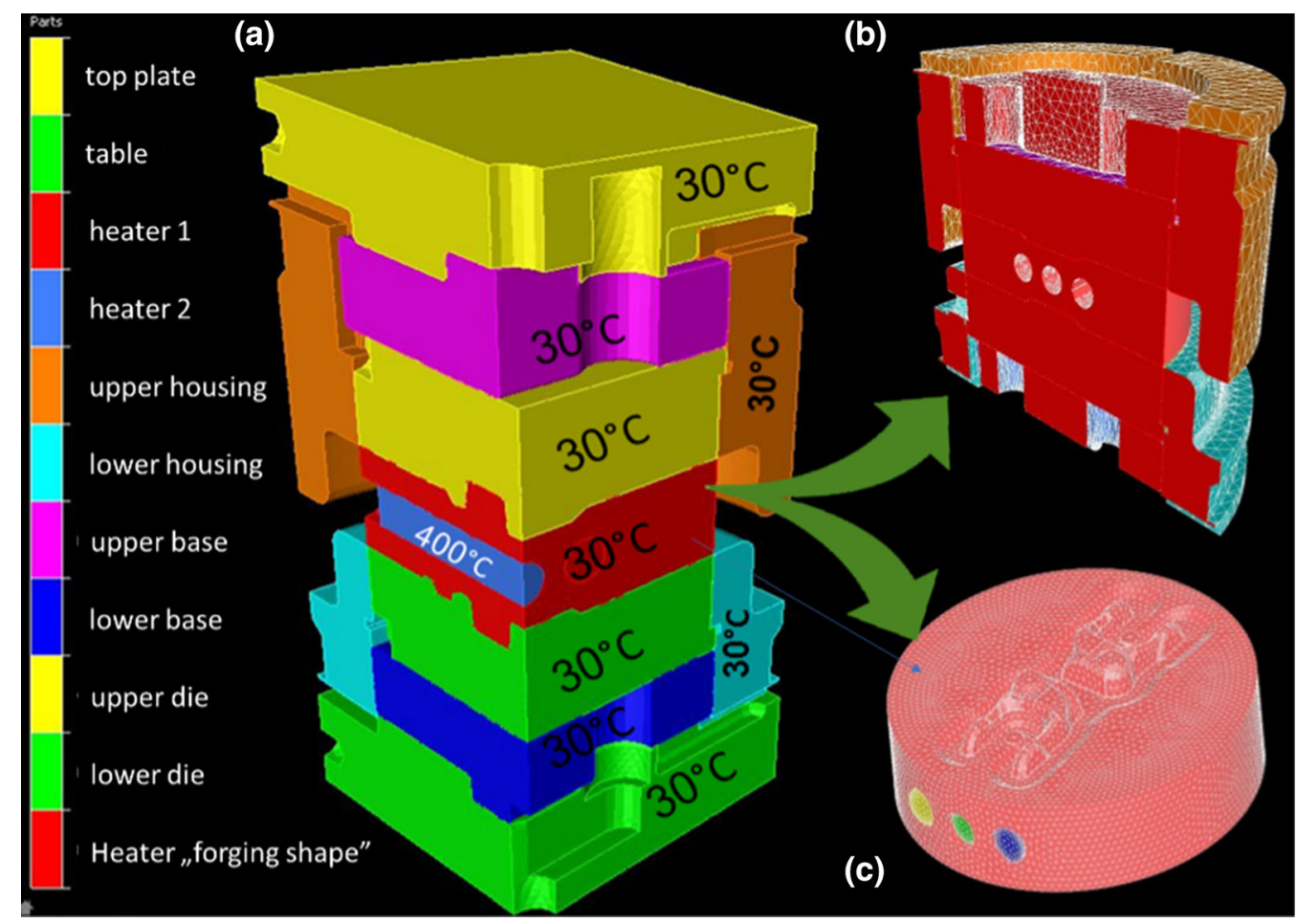

Fig. 12-Numerical model of the stand used to heat the tools with a special heater in the shape of a forging: (a) set of tools with housings, bases mounted in the housings $(1 / 4$ model); $(b)$ cross section of the digitized model with the heating element equipped with three heaters; $(c)$ FEM model of a "forging shape" heater.

Based on the preliminary verification, it was established that heating with the proposed method (the assumed heat transfer coefficient at the level of $2000 \mathrm{~W} /$ $\mathrm{m}^{2} \mathrm{~K}$ ) is much better than heating by means of a waste material or applying cartridge heaters in the housing. Additionally, for this reason, a decision was also made to model the tool heating process during unexpected stoppages or maintenance shutdowns. Figure 14(a) shows a tool set with the assumed initial temperatures, while Figure 14(b) presents the results obtained in the process of additional heating for the assumed initial boundary conditions.
The modeling results show the advantage of the new method of heating usinf heaters in the shape of forgings, as it shortened the heating time to 35 minutes. For additional heating for the assumed "typical" conditions after a maintenance shutdown, the heating time was about 15 minutes, which, in both cases, is a satisfactory result. Nevertheless, it is still a relatively long heat transfer time, and the limited thermal conductivity in the heater's contact with the die can prolong it. This can be especially important for aluminum and titanium, where the temperature of the tools is the key factor and is within a narrow range. This is why a prototype was not 


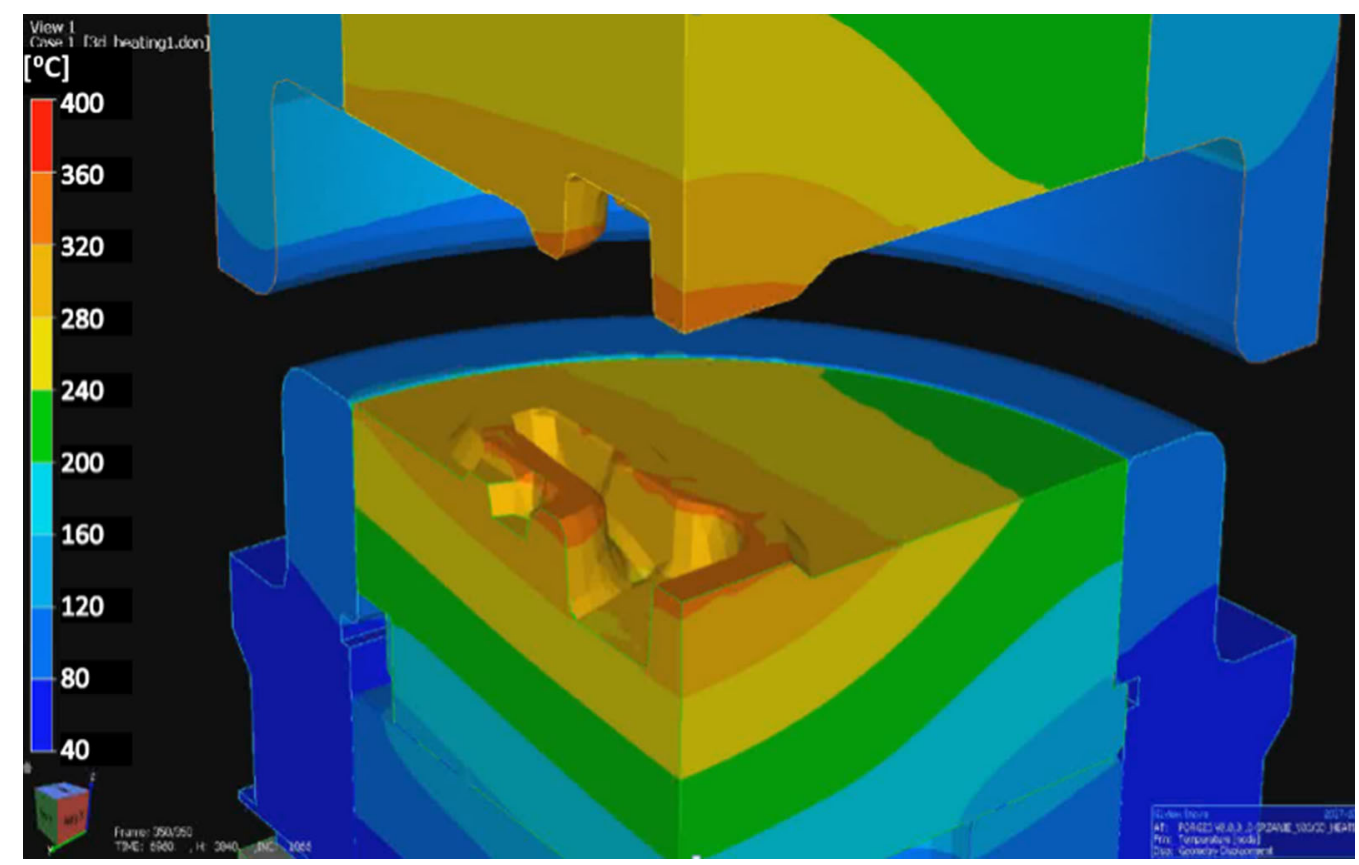

Fig. 13-Temperature field distributions in the tools. Numerical modeling results for the heat transfer coefficient $2000 \mathrm{~W} / \mathrm{m}^{2} \mathrm{~K}$, after about $10,000 \mathrm{~s}(3 \mathrm{~h})$ of heating and annealing.
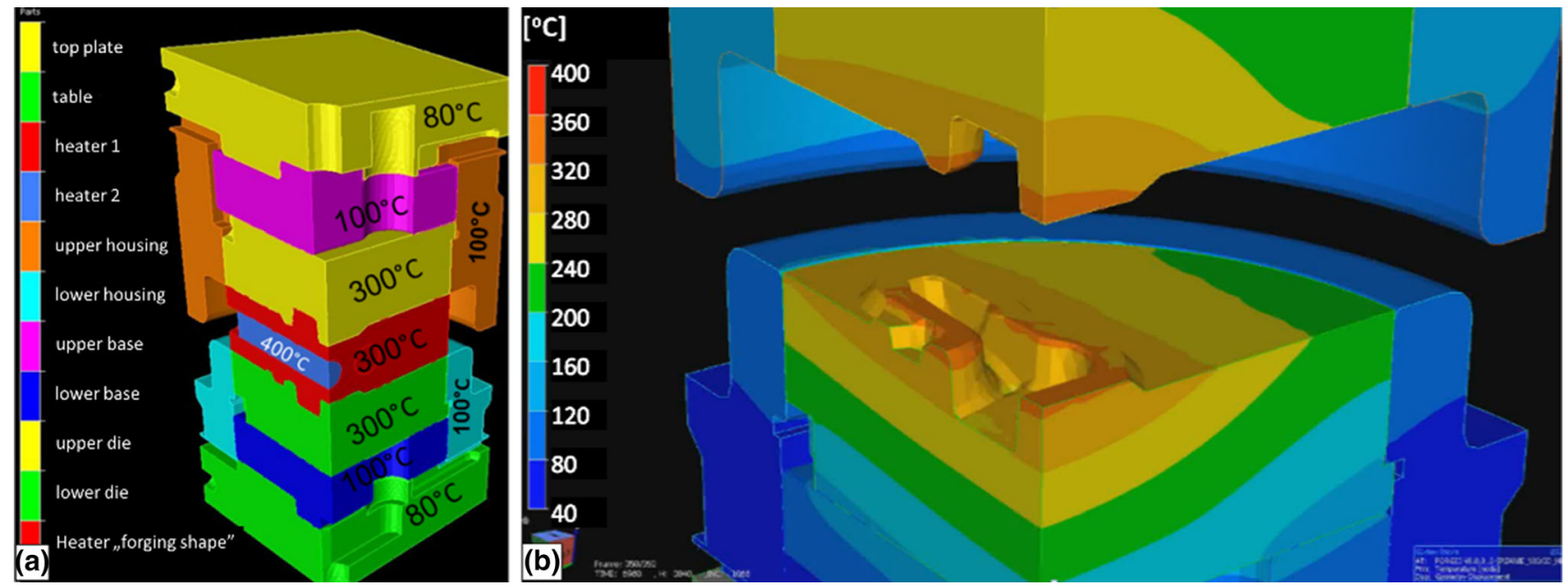

Fig. 14 - Results of numerical modeling during the additional heating with the assumed initial boundary conditions: $(a)$ view of the tool set with the initial temperatures for the particular tools, $(b)$ temperature field distributions after about 15 min.

constructed; instead, other heating methods were examined, e.g., induction heating, which, based on the current review of the solutions applied in the field, is currently one of the newest and most commonly applied methods of heating forging instrumentation.

\section{Induction Heating}

The numerical model of induction heating was developed, and the obtained preliminary results showed the enormous potential this solution (Figure 15), which motivated us to construct a prototype test stand implementing this heating method. Induction heating has been the subject of many studies, and its usefulness and efficiency have been confirmed in both in numerical modeling ${ }^{[41]}$ and industrial applications. ${ }^{[42]}$

Based on the performed modeling for the assumed values of heat transfer coefficients, the obtained time of heating from ambient temperature to about $300{ }^{\circ} \mathrm{C}$ on the surface of the impressions equaled about $18 \mathrm{~min}$. This result was assumed to be sufficient and was the best result of the analyzed tool heating variants. Therefore, we decided to construct such a system and test it. To verify the proposed solution, a prototype version was built (Figure 16(a)). The effectiveness of the induction heater was verified by measuring the temperature in the dies. To that end, for one tool, two thermocouples were mounted: one right beneath the surface, at the depth of 


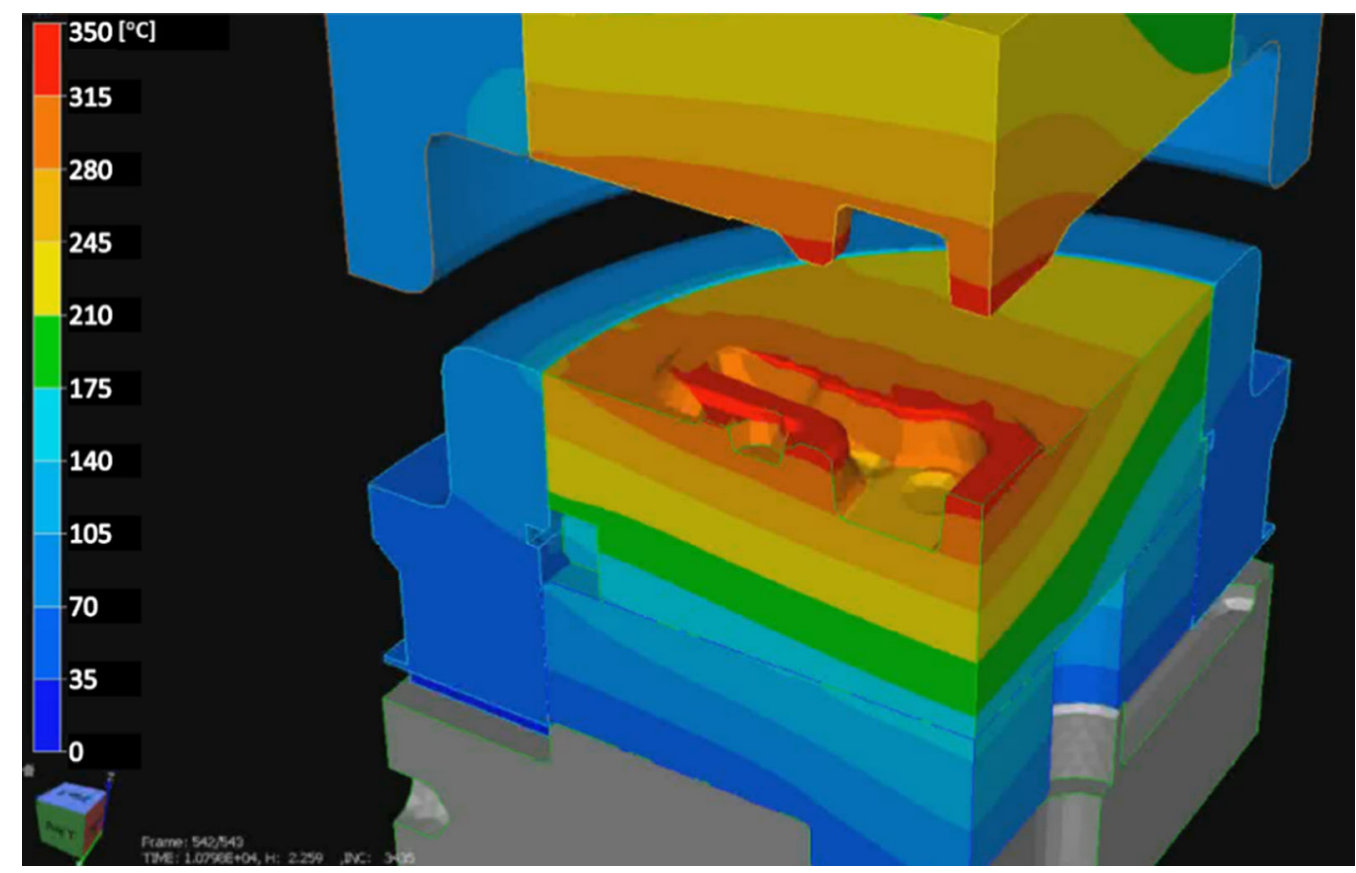

Fig. 15-Preliminary numerical modeling results for the elaborated induction tool heating system also designed for their additional heating during maintenance shutdowns.
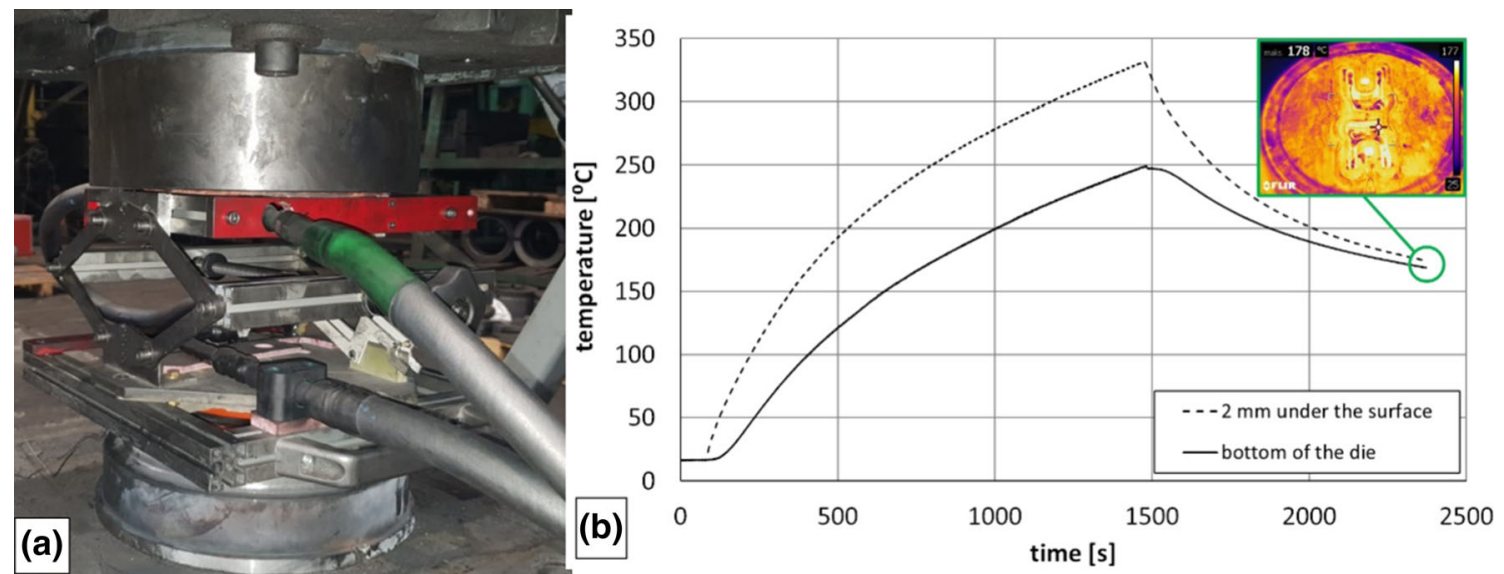

Fig. 16-(a) Prototype stand for induction heating of the tools; $(b)$ tool temperature measurement results obtained during the heating on the stand.

about $2 \mathrm{~mm}$, and the other on the bottom of the die. During the heating, the temperature changes in those areas were recorded as a function of time and are presented in Figure 16(b).

The performed experimental studies established that the developed solution of induction heating on the prototype stand enables effective heating. To obtain temperatures within the range of $200{ }^{\circ} \mathrm{C}$ to $250{ }^{\circ} \mathrm{C}$, it is enough to perform a single heating procedure 20 minutes, which constitutes less than half of the time needed for the charge material heating method applied so far (Figure 7(a)). The diagram in Figure 16(b) shows that the tools are not overheated and the temperature, even 10 minutes after the induction heaters have finished their work in the whole volume of the tool, exceeds
$200{ }^{\circ} \mathrm{C}$, which is sufficient for the forging process to begin.

Therefore, induction heating can be successfully applied to preheat tools in forging processes. Induction heaters were also considered for use in the additional heating of tools during maintenance shutdowns when the temperature drops below $200{ }^{\circ} \mathrm{C}$. Then, a short heating cycle is necessary, which will raise the temperature to the desired value. Figure 17 shows the temperature changes in the tool during short (10 minutes) heating cycles, separated by a 20 -min break.

The results concerning the additional heating of tools suggest that, in the case of a forging stoppage of 15 to 20 minutes, with the use of the developed solution, it is possible to additionally heat the working patterns of the 


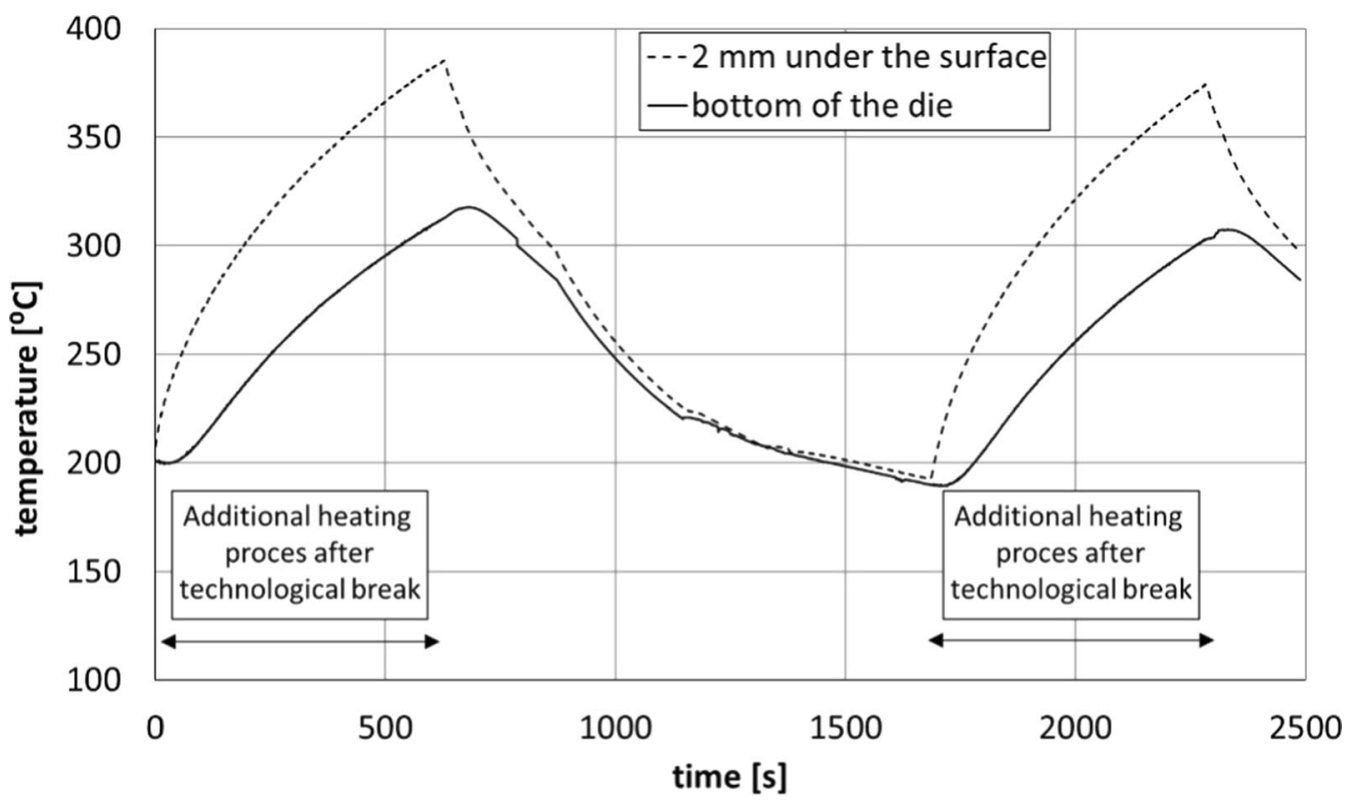

Fig. 17-Temperature measurement results during additional heating at the time of maintenance shutdowns.

tools from the temperature below $200{ }^{\circ} \mathrm{C}$ to their working temperature within the time of 5 to 10 minutes. The precise values of the additional heating time depending on the value of the temperature drop during a maintenance shutdown have to be determined individually for each type of tool used in the hot forging process. Nevertheless, this is much more effective than the charge material heating method used so far, which is shown in Figure 6(a).

\section{E. Summary and Conclusions}

The discussed results of theoretical and experimental studies point to the great potential of the elaborated solution, for both heating the tools from ambient temperature to the working temperature (about $200{ }^{\circ} \mathrm{C}$ to $250{ }^{\circ} \mathrm{C}$ ) and additional heating during stoppages, breakdowns or maintenance shutdowns. In the future, the authors are planning to perform investigations aiming to develop a tool heating system that will not require interrupting the production process but that, through continuous monitoring of the tool temperature, will make it possible to activate the tool heating system directly during the process to obtain a constant tool working temperature, assumed for the given process.

The performed studies and the obtained results led to the following conclusions:

- The proposed procedure of charge material heating enables effective preheating of forging tools, without the risk of overheating or underheating, within the time of about 50 minutes by implementing three heating cycles.

- The innovative method of using a heater introduced into the housing does not yield sufficient results, as more heat is released into the rest of the tooling than into the die. Also, heating of the housings may cause their expansion and the formation of clearances between the die and its housing, which is disadvantageous in relation to the instrumentation's construction.

- Preheating using a heater in the shape of a forging provides satisfactory results (heating time about 35 minutes) and provides a new alternative heating method, which is more energy efficient owing to the matching of the heater's shape to that of the forging die.

- Induction heating is the fastest and most effective heating method, which makes it possible to reach the desired temperature already after 15 to 20 minutes of heating. It can also be successfully applied for additional heating during maintenance shutdowns or breakdowns in short heating cycles of 5 to 10 minutes.

\section{ACKNOWLEDGMENTS}

This study was funded by National Center for Research and Development, Poland (grant no. Lider X/0028/L-10/2018).

\section{OPEN ACCESS}

This article is licensed under a Creative Commons Attribution 4.0 International License, which permits use, sharing, adaptation, distribution and reproduction in any medium or format, as long as you give appropriate credit to the original author(s) and the source, provide a link to the Creative Commons licence, and indicate if changes were made. The images or other third party material in this article are included in the article's Creative Commons licence, unless indicated 
otherwise in a credit line to the material. If material is not included in the article's Creative Commons licence and your intended use is not permitted by statutory regulation or exceeds the permitted use, you will need to obtain permission directly from the copyright holder. To view a copy of this licence, visit http://creat ivecommons.org/licenses/by/4.0/.

\section{REFERENCES}

1. Z. Gronostajski, Z. Pater, L. Madej, A. Gontarz, L. Lisiecki, A. Lukaszek-Solek, J. Luksza, J. Mróz, Z. Muskalski, W. Muzykiewicz, M. Pietrzyk, R.E. Śliwa, J. Tomczak, S. Wiewiórowska, G. Winiarski, and J. Zasadziński: S. Ziółkiewicz:Arch. CivMech. Eng., 2019, vol. 19, pp. 898-41.

2. Forging Business Outlook, https://www.forgingmagazine.com/iss ues-and-ideas/2019-forging-business-outlook. Accessed 26 November 2019.

3. B.-A. Behrens, A. Bouguecha, M. Vucetic, A. Chugreev: Advanced Wear Simulation for Bulk Metal Forming Processes. MATEC Web of Conferences, 2016, 80, 1-4.

4. A.K. Singh: Wear, 1973, vol. 25, pp. 271-79.

5. R. Sharma and D.J. Arrowsmith: Wear, 1981, vol. 74, pp. 1-10.

6. E. Summerville, K. Venkatesan, and C. Subramanian: Mater. Design, 1995, vol. 16, pp. 289-94.

7. M. Hawryluk: Arch. Civ. Mech. Eng, 2016, vol. 16, pp. 845-66.

8. M. Hawryluk, Z. Gronostajski, M. Kaszuba, S. Polak, P. Widomski, J. Smolik, and J. Ziemba: Int. J. Mach. Tools Manuf., 2017, vol. 114, pp. 60-71.

9. M. Hawryluk, P. Widomski, and J. Ziemba: Obróbka Plastyczna Metali $=$ Metal Forming, 2017, vol. 28, pp. 75-92.

10. D.J. Politis, N.J. Politis, J. Lin, and T.A. Dean: Int. J. Adv. Manuf. Technol., 2018, vol. 97, pp. 2809-33.

11. H-W. Brockhaus, A. Guderjahn, I. Schruff, improving the performance of forging tools - a case study. https://www5.kau.se/site s/default/files/Dokument/subpage/2010/02/9_113_128_pdf_16762. pdf. Accessed 26 November 2019.

12. The Three Essential Forging Temperatures. https://www.williams onir.com/blog/the-3-essential-forging-temperatures/. Accessed 26 November 2019.

13. Simulation of die heating for forgings and pressure castings by convective heating systems. https://mhi-inc.com/PG2/Die $\% 20 \mathrm{Hea}$ ting \% 20Comparison\%20Airtorch\%20vs. \%20Flame.PDF.Access ed 26 November 2019.

14. P. Widomski, M. Skwarski, M. Rychlik:Interdisciplinary Journal of Engineering Sciences, 2017, vol. V, http://ijes.pwr.wroc.pl.

15. C. A. Blue, V. K. Sikka, E. K. Ohriner, P. G. Engleman, G. F. Mochnal, A. Underys, W-T. Wu, M. C. Maguire, R. Mayer: Infrared Heating Of Forging Billets And Dies.https://www.dyka st.com/user/files/A_Forged_IinfraredHeatingReport1.pdf. Accessed 26 November 2019.

16. Z. Gronostajski, M. Hawryluk, J. Wollmann, M. Kaszuba, G. Misiun, and P. Sadowski: Arch. Metall. Mater., 2015, vol. 60, pp. $2773-81$.

17. M.A. Kellow, A.N. Bramley, and F.K. Bannister: Int. J. Mach. Tool Des. Res., 1969, vol. 9, pp. 239-60.

18. Hot Die and Isothermal Forging. https://www.forging.org/forgin g/design/5224-hot-die-and-isothermal-forging.html. Accessed 26 November 2019.
19. US Patent US20150013421A1, Method for heating forging die device, 2012.

20. US Patent no WO2015167407A1, Forging dies with internal heating system, 2015.

21. M. Sawamura, Y. Yogo, S. Kondo, T. Tanaka, K. Nakanishi, T. Suzuki, and A. Watanabe: $R \& D$ Rev. Toyota CRDL, 2005, vol. 40 , pp. $50-56$.

22. T. Tanaka, K. Nakanishi, Y. Yogo, S. Kondo, T.Y. Tsuchiya, and A. Watanabe: $R \& D$ Rev. Toyota $C R D L, 2005$, vol. 40, p. 1.

23. K. Lange: Handbook of Metal Forming, Society of Manufacturing Engineers, Dearborn, 1985.

24. T. Altan: Metal Forming Handbook, Springer, Berlin, 1998.

25. T. Altan, M. Shirgaokar, Advanced die materials and lubrication systems to reduce die wear in hot and warm forging, https://www.f orging.org/uploaded/content/media/AltansPres.pdf. Accessed 26 November 2019.

26. B.-A. Behrens, J. Puppa, A. Huskic, K. Brunotte, A. Bouguecha, and T. Prüß: Prod. Eng., 2016, vol. 10, pp. 599-606.

27. B.-A. Behrens, R. Lachmayer, I. Malik, M. Bonhage, B. Sauthoff, and P. Gottwald: WT Werkstattstechnik, 2015, vol. 105, pp. 692-96.

28. K. Staples, V. Sarvepalli, M. Fu, J. A.Sekhar, US Patent 5,963, 709 Oct. 51999.

29. F.H. Jeddy, M.A. Jog, J.A. Sekhar, R.D. Markle, V. Sarvepalli, and R. Burada: Adv. Mater. Process., 1999, vol. 156, pp. 213-15.

30. M. Fu, K. Staples, and V. Sarvepalli: JOM, 1998, vol. 50, pp. $42-44$.

31. Preheating moulds and dies quickly, homogeneously and without damaging materials. https://www.metec-tradefair.com/en/News/T opics/Preheating_moulds_and_dies_quickly, homogeneously_an d_without_damaging_materials. Accessed 26 November 2019.

32. Evaluation of various methods to pre-heat of forging dies. http:// www.michigantechame.com/sites/default/files/Evaluation $\% 20$ o f $\% 20$ Various $\% 20$ Methods $\% 20$ to $\% 20$ Pre-Heat $\% 20$ Forging $\% 20$ Dies.pdf. Accessed 26 November 2019.

33. Infrared Die Pre-Heaters. https://www.infraredheating.com/indus trial-ovens/infrared-die-pre-heaters/. Accessed 26 November 2019.

34. I.L. Akaro: Kuznechno-Shtampovochnoe Proizvodstvo (Obrabotka Metallov Davleniem), 2003, vol. 5, pp. 40-43.

35. B. Mueller, N. Gerth, I. Hamann, A. Fischer, T. Rädel, M. Gebauer, and T. Töppel: Giesserei, 2013, vol. 100, pp. 34-41.

36. Z. Gronostajski, P. Widomski, M. Kaszuba, M. Zwierzchowski, and A. Barełkowski: Rudy i Metale Nieżelazne, 2018, vol. 63, pp. $9-18$.

37. L. A. Dobrzański: Metalowe materiały inżynierskie. Wydawnictwo Naukowo Techniczne, 2004.

38. B. Buchmayr: BHM Berg- und Hüttenmännische Monatsheft, 2017, vol. 162 , pp. 88-93.

39. S. Singh, K. Sorensen, and T. Condra: Appl. Therm. Eng., 2016, vol. 107 , pp. 612-24.

40. M. Rywotycki, Z. Malinowski, J. Falkus, K. Sołek, A. Szajding, and K. Miłkowska-Piszczek: Arch. Metall. Mater., 2016, vol. 61, pp. 341-46.

41. X. Fu, B. Wang, X. Tang, H. Ji, and X. Zhu: Appl. Therm. Eng., 2017, vol. 114, pp. 1-9.

42. M.C. Song and Y.H. Moon: Appl. Therm. Eng., 2016, vol. 98, pp. 98-109.

Publisher's Note Springer Nature remains neutral with regard to jurisdictional claims in published maps and institutional affiliations. 